\title{
DETERMINATION OF TRICLOSAN IN INDONESIAN HOUSEHOLD, PERSONAL CARE, AND COSMETIC PRODUCTS BY ISOCRATIC REVERSED-PHASE HIGH- PERFORMANCE LIQUID CHROMATOGRAPHY
}

\author{
N. Rusdiana ${ }^{1,2,}{ }^{凶}$, M.S. Wibowo ${ }^{1}$ and R.E. Kartasasmita ${ }^{1}$ \\ ${ }^{1}$ Department of Pharmacochemistry, School of Pharmacy, Bandung Institue of Technology, Jl. \\ Ganesha 10 Bandung 40132, West Java Indonesia \\ ${ }^{2}$ College of Pharmacy Muhammadiyah Tangerang, J1 Syech Nawawi 13 Tangerang 15720, \\ Banten Indonesia \\ Corresponding Author: nita.rusdiana270@gmail.com
}

\begin{abstract}
Triclosan (5 - chloro - 2 - (2,4 - dichlorophenoxy) phenol) is a biocide compound commonly added to the various household, personal care, and cosmetic products. This research aims to determine triclosan content in those products by a chromatographic method. Product samples containing were analyzed using HPLC equipped with C18 column UV detection at $280 \mathrm{~nm}$ and mobile phase using a mixture of acetonitrile - double distilled water (75:25). All samples were confirmed to contain triclosan at levels not more than permissible level by the regulation in Indonesia.

Keywords: HPLC, Household, Personal Care, Cosmetic, Triclosan.
\end{abstract}

RASĀYAN J. Chem., Vol. 14, No.2, 2021

\section{INTRODUCTION}

Triclosan (1) has been used for more than 40 years as a preservative in cosmetics ${ }^{1-3}$ and almost in all personal care ${ }^{4-6}$ and household products. ${ }^{7-9}$ Triclosan is a very strong microbial inhibitor, which can be used to control dental infections caused by bacteria. ${ }^{10}$ The chemical name of triclosan is 5 - chloro - 2 - $(2,4$ - dichlorophenoxy) phenol, while its molecular formula is $\mathrm{C}_{12} \mathrm{H}_{7} \mathrm{Cl}_{3} \mathrm{O}_{2}$ and its molecular weight is $289.5 \mathrm{~g}$ per mol. This compound is a white crystalline powder, which easily dissolves in alkaline solutions and organic solvents, soluble in acetone, ethanol, methanol, and slightly soluble in water. Several chromatographic methods have been reported for the determination of triclosan levels in various samples. Especially HPLC methods have been designed that allow the determination of the effectiveness of separation and quantification of samples. ${ }^{11-16}$ In our experiment, a reverse phase HPLC method with an isocratic gradient system has been prepared for the determination of triclosan in the household, personal care, and cosmetic products.<smiles>Oc1cc(Cl)ccc1Oc1ccc(Cl)cc1Cl</smiles>

Fig.-1: Chemical Structures of Triclosan (1)

\section{Instrumentation}

\section{EXPERIMENTAL}

The sample analysis products were performed on a Waters e2695 series HPLC system (Millford, USA) equipped with UV-Vis detector and Agilent ZORBAX Eclipse Plus C-18 column (5 $\mu \mathrm{m}, 4,6$ x $150 \mathrm{~mm})$ (USA). The signal output was monitored and integrated using Waters Empower 3 software. 
RASĀYAN J. Chem.

Vol. 14 | No. 2 |1435-1440| April - June | 2021

\section{Chemicals and Solvents}

Triclosan was purchased from Sigma Aldrich (purity 99.9 percent), while acetonitrile and methanol (Merck) double distilled water were purchased from IPHA Laboratories (Bandung, Indonesia).

\section{Mobile Phase Preparation}

A $500 \mathrm{~mL}$ mobile phase was prepared to consist of a mixture of $375 \mathrm{~mL}$ acetonitrile and $125 \mathrm{~mL}$ of doubledistilled water.

\section{Diluent Preparation}

The mobile phase was used as diluent.

\section{Standard Preparation: (For Triclosan $1000 \mu \mathrm{g} / \mathrm{mL}$ )}

$25 \mathrm{mg}$ triclosan was accurately weighed and transferred into a $25 \mathrm{~mL}$ measuring flask and dissolved with the mobile phase. To enhance the solubility, the mixture was ultrasonicated until triclosan was completely dissolved.

\section{Sample Preparation}

A sample of products containing triclosan was chosen to represent solid, semi-solid, and liquid preparations. $0.5 \mathrm{~g}$ of solid sample was accurately weighed in a $15 \mathrm{~mL}$ plastic centrifuge tube, added with $7.5 \mathrm{~mL}$ of acetonitrile gradually, mechanically agitated for 3 minutes, ultrasonicated for 5 minutes, and then centrifuged for 10 minutes. The supernatant was quantitatively pipetted.

$0.5 \mathrm{~g}$ of semi-solid samples were accurately weighed in a $10 \mathrm{~mL}$ volumetric flask, added with $3 \mathrm{~mL}$ of methanol, ultrasonicated for 10 minutes, and filled with methanol to mark (solution 1), and then shaken. $2.0 \mathrm{~mL}$ of solution 1 was pipetted into a $10 \mathrm{~mL}$ volumetric flask, diluted with methanol to mark, and then shaken.

$250 \mu \mathrm{L}$ of the liquid sample was pipetted into a $10 \mathrm{~mL}$ volumetric flask, added by $\mathrm{mL}$ of acetonitrile and double distilled water $(75: 25)$ gradually. Afterward, it was ultrasonicated for 10 minutes, diluted with mobile phase to mark, and then shaken.

All samples were filtered using a $0.45 \mu \mathrm{m}$ membrane filter. The resulting filtrate was then used as the solution to be tested.

\section{Chromatographic Conditions}

The column oven for ZORBAX Eclipse plus $5 \mu \mathrm{m}(4.6 \mathrm{x} 150 \mathrm{~mm})$ Columns was set at $30^{\circ} \mathrm{C}$. The mobile phase was controlled at a flow rate of $0.6 \mathrm{~mL}$ per min. The sample injection volume was $10 \mu \mathrm{L}$, the detector was set at $280 \mathrm{~nm}$ and the chromatography runtime was 10 minutes.

\section{Analysis of Triclosan in the Household, Personal Care, and Cosmetic Products}

Identification of triclosan in the samples was conducted by comparison of triclosan peak retention time in the chromatogram of standard solution with those of sample solutions. If the retention times of the two peaks in these chromatograms were not significantly different, the corresponding peak in the chromatogram of the sample was identified as triclosan. The determination of triclosan in the samples was conducted by the external calibration method. To determine the compliance of triclosan levels in the sample, the results were compared with the maximum use level according to regulation in Indonesia (0.3-2\%).

\section{Method Development}

\section{RESULTS AND DISCUSSION}

To develop a suitable and robust method for the determination of triclosan, an HPLC system equipped with a ZORBAX Eclipse plus $5 \mu \mathrm{m}(4.6 \times 150 \mathrm{~mm})$ column controlled at $30^{\circ} \mathrm{C}$ and $\mathrm{UV}$ detection at $280 \mathrm{~nm}$ was used. Different mobile phases were tested to achieve the best chromatographic performance. A mixture of acetonitrile and double distilled water with a ratio $75: 25 \mathrm{v} / \mathrm{v}$ and a flow rate of $0.6 \mathrm{~mL} /$ minute gave the best and consistent chromatogram. The following chromatogram (Fig.-2) shows repetitive peaks of the standard of triclosan which were consistently eluted at $4.434 \pm 0.01$ minutes. 
RASĀYAN J. Chem.

Vol. 14 | No. 2 |1435-1440| April - June | 2021

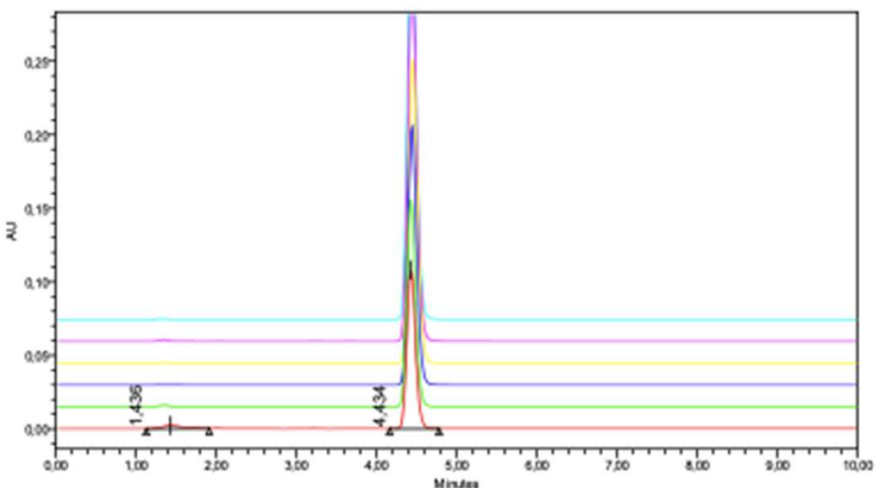

Fig-2: HPLC Chromatogram of Triclosan Standard

The results of system suitability of criteria for triclosan revealed that all parameters fulfilled the requirements. Triclosan was eluted and gave nearly a symmetric peak (low tailing factor), a high number of theoretical plates, and gut injection repeatability. The overall system suitability criteria result Table-1.

Table-1: System Suitability of Criteria for Triclosan Standard $(n=9)$

\begin{tabular}{c|c|c}
\hline Parameter & Triclosan & Acceptable limit ${ }^{17}$ \\
\hline $\mathrm{t}_{\mathrm{R}}( \pm \mathrm{SD})$ in minutes & $4.434(0.01)$ & - \\
\hline Tailing factor & 1.112 & $\leq 2$ \\
\hline Number of theoretical plates & 710098 & $>2000$ \\
\hline Injection repeatability (\% RSD) & 0.40 & $\leq 1$ \\
\hline
\end{tabular}

\section{Linearity}

Figure-3 shows the calibration curve of triclosan in the concentration range of $10-60 \mathrm{ppm}$ with a linear regression equation of $y=19410 x+39153$ and $r^{2}$ value of 0.9997 . This result indicates that there is a linear relationship between the measurement responses and the concentration of triclosan. In addition, the linearity was tested by comparing the relative procedural standard deviation of linear regression (linear $\mathrm{V}_{\mathrm{x} 0}$ ) with that of quadratic regression quadratic (quadratic $\mathrm{V}_{\mathrm{x} 0}$ ). Since linear $\mathrm{V}_{\mathrm{X} 0}$ is less than quadratic $\mathrm{V}_{\mathrm{X} 0}$, the linear regression is better than quadratic regression, which is proof of linearity. ${ }^{18}$ The $\mathrm{V}_{\mathrm{X} 0}$ calculation results are presented in Table- 2 .

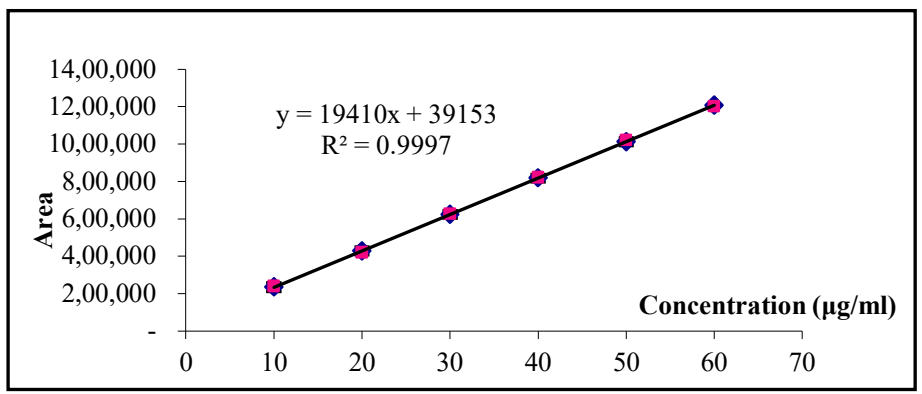

Fig.-3: Linear Calibration Curve of Triclosan

Table-2: Linear and Quadratic $\mathrm{V}_{\mathrm{X} 0}$ Calculation Results

\begin{tabular}{c|c|c|c|c|c|c|c|c}
\hline No & $\mathrm{C}(\mathrm{mg} / \mathrm{L}), \mathrm{X}_{\mathrm{i}}$ & $\mathrm{AUC}, \mathrm{Y}_{\mathrm{i}}$ & $\mathrm{X}_{\mathrm{i}}^{2}$ & $\mathrm{X}_{\mathrm{i}}^{3}$ & $\mathrm{X}_{\mathrm{i}}^{4}$ & $\mathrm{Y}_{\mathrm{i}}^{2}$ & $\mathrm{X}_{\mathrm{i}} \mathrm{Y}_{\mathrm{i}}$ & $\mathrm{X}_{\mathrm{i}}^{2} \mathrm{Y}_{\mathrm{i}}$ \\
\hline 1 & 10 & 238473 & 100 & 1000 & 10000 & 56589530552 & 2384733 & 23847333 \\
\hline 2 & 20 & 418786 & 400 & 8000 & 160000 & 175381992708 & 8375727 & 167514533 \\
\hline 3 & 30 & 624562 & 900 & 27000 & 810000 & 390077691844 & 18736860 & 562105800 \\
\hline 4 & 40 & 820131 & 1600 & 64000 & 2560000 & 672614310954 & 32805227 & 1312209067 \\
\hline 5 & 50 & 1019780 & 2500 & 125000 & 6250000 & 1039951248400 & 50989000 & 2549450000 \\
\hline 6 & 60 & 1201551 & 3600 & 216000 & 12960000 & 1443725589625 & 72093080 & 4325584788 \\
\hline$\Sigma$ & 210 & 4323284 & 9100 & 441000 & 22750000 & 3778620373082 & 185384626 & 8940711522 \\
\hline \multicolumn{7}{|c|}{0.863} \\
\hline
\end{tabular}


RASĀYAN J. Chem.

Vol. 14 | No. 2 |1435-1440| April - June | 2021

\section{Precision}

For precision determination, a sample matrix was spiked with triclosan standard solution at $30 \mathrm{ppm}$. Repetitive determination of triclosan in that spiked sample gave RSD value of $0.56 \%(\mathrm{~N}=9)$. According to $\mathrm{AOAC}^{17}, \mathrm{RSD}$ value for repetitive determination in the range 10-100 ppm and 100-1000 ppm should be not more than $4-6 \%$ and $3 \%-4 \%$, respectively. In addition, the calculation of Horrat value gave a result $0.19 \%$, while the acceptance value is $\leq 2 \%{ }^{17}$. These results highlighted that the analytical method used has good precision. The result of the precision determination is depicted in Table- 3.

Table-3: The Result of Precision Determination of Triclosan ( $\mathrm{n}=9$ )

\begin{tabular}{c|c}
\hline $\begin{array}{c}\text { Sample No. } \\
\text { Spiked concentration 30 ppm) }\end{array}$ & $\begin{array}{c}\text { Obtained Concentration } \\
(\mu \mathrm{g} / \mathrm{mL})\end{array}$ \\
\hline 1 & 29.62 \\
\hline 2 & 29.76 \\
\hline 3 & 30.09 \\
\hline 4 & 30.03 \\
\hline 5 & 30.03 \\
\hline 6 & 29.93 \\
\hline 7 & 30.06 \\
\hline 8 & 30.10 \\
\hline 9 & 30.03 \\
\hline$x$ & 30.00 \\
\hline SD & 0.2 \\
\hline RSD (\%) & 0.56 \\
\hline RSD Horwitz & 3.38 \\
\hline HORRAT & 0.19 \\
\hline
\end{tabular}

\section{Accuracy}

The accuracy was determined from the $\%$ of recovery determination of spiked triclosan standard solution to the sample matrix at the concentration level of $80 \%, 100 \%$ and $120 \%$ of the predicted levels of analyte in the sample. The results of these determinations were in the range of $97 \%-104 \%$, while the acceptable $\%$ of recovery of $\mathrm{AOAC}^{17}$ for the concentration range of $10-100 \mathrm{ppm}$ is $80-115 \%$. Thus, the $\%$ of recovery obtained can be accepted based on the AOAC criteria, and hence the method shows good accuracy. The results of accuracy determination were presented in Table-4.

\section{Limit of Detection (LOD) and Limit of Quantification (LOQ)}

The LOD and LOQ values of triclosan were determined using statistical calculation method ${ }^{17}$ from the calibration curve equation. Table-5 shows the results of LOD and LOQ calculations.

Table-4: Accuracy in the Assay Determination of Triclosan

\begin{tabular}{c|c|c|c|c}
\hline Spike Level & Spiked (ppm) & Obtained (ppm) & \% of Recovery & Mean \% Recovery \\
\hline \multirow{3}{*}{ Of $80 \%$} & 27.3 & 22.97 & 74 & \multirow{2}{*}{$97 \%$} \\
\cline { 2 - 4 } & 29 & 22.97 & 10 & \\
\cline { 2 - 4 } & 29.7 & 22.97 & 115 & \multirow{3}{*}{$94 \%$} \\
\hline \multirow{3}{*}{$100 \%$} & 31.5 & 23.33 & 86 & \multirow{2}{*}{$104 \%$} \\
\cline { 2 - 4 } & 32.1 & 23.33 & 92 & \\
\cline { 2 - 4 } & 33.4 & 23.33 & 106 & \\
\hline
\end{tabular}

Table-5: LOD and LOQ of Triclosan

\begin{tabular}{c|c|r|r|r|r}
\hline Sample No. & Concentration $(\mathrm{ppm})$ & \multicolumn{1}{c|}{$\mathrm{yr}$} & \multicolumn{1}{c|}{ yi } & \multicolumn{1}{c|}{ yr-yi } & \multicolumn{1}{|c}{$(\mathrm{yr}-\mathrm{yi})^{2}$} \\
\hline 1. & 10.02 & 238473.33 & 233834.52 & 4638.80 & 21518552.64 \\
\hline 2. & 20.05 & 418786.33 & 428516.04 & -9729.71 & 94667338.41 \\
\hline 3. & 30.08 & 624562.00 & 623197.57 & 1364.42 & 1861667.04 \\
\hline 4. & 40.11 & 820130.66 & 817879.09 & 2251.57 & 5069579.17 \\
\hline 5. & 50.14 & 1019780.00 & 1012560.61 & 7219.38 & 52119476.46 \\
\hline
\end{tabular}


RASĀYAN J. Chem.

Vol. 14 | No. 2 |1435-1440| April - June | 2021

\begin{tabular}{|c|c|c|c|c|c|}
\hline 6. & 60.17 & 1201551.33 & 1207242.14 & -5690.81 & 32385336.66 \\
\hline \multicolumn{5}{|c|}{$\sum(\mathrm{yr}-\mathrm{yi})^{2}$} & 207621950.4 \\
\hline \multicolumn{5}{|c|}{ Sy/x } & 5882.49 \\
\hline \multicolumn{5}{|c|}{$(\mathrm{Sy} / \mathrm{x}) / \mathrm{b}$} & $0.30 \mathrm{ppm}$ \\
\hline \multicolumn{5}{|c|}{ LOD } & $1.00 \mathrm{ppm}$ \\
\hline \multicolumn{5}{|c|}{ LOQ } & $3.03 \mathrm{ppm}$ \\
\hline
\end{tabular}

This method has the LOD and LOQ values of 1.00 and $3.03 \mathrm{ppm}$, respectively. Since the expected concentration of triclosan in the samples will be higher than LOQ values, this method will be able to determine triclosan in the samples with good precision and accuracy.

\section{Identification and Determination of Triclosan in the Samples}

The identification of triclosan in the samples was conducted based on the presence of peaks in the chromatograms eluted at the retention times not significantly different from those of triclosan standard. In addition, in the case of doubt, a co-chromatography procedure was carried out, i.e., triclosan standard solution was spiked into the sample solution. The chromatograms revealed that the retention times of triclosan were in the range of $4.09-4.36$ with an average of 4.155 minutes, while the retention of standard triclosan was averagely 4.434 minutes. The slight difference in the retention time is still acceptable due to possible matrix influences in the sample solutions. Commonly, the influences of the matrix could lead to column enrichment and result in earlier retention time. Fig.-4 shows the overlay chromatograms of several sample solutions.

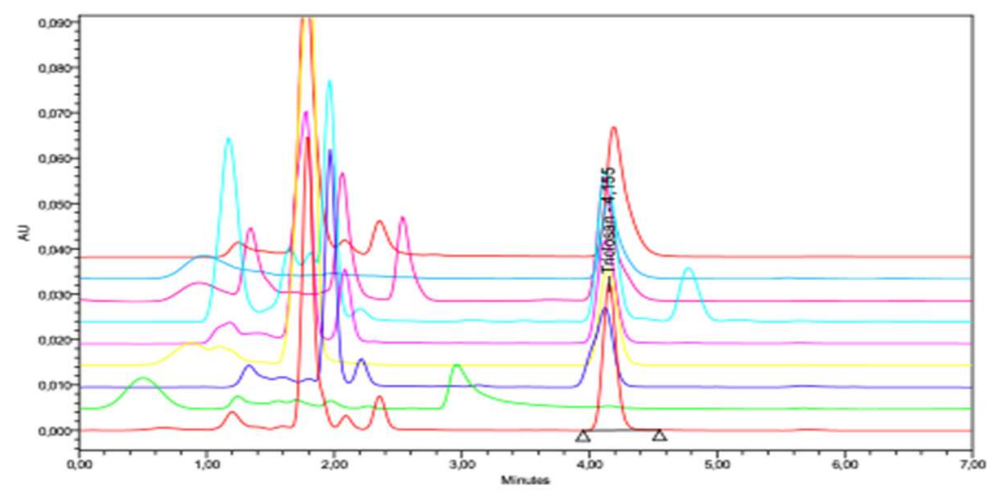

Fig.-4. Overlay Chromatograms of Sample Solutions

Triclosan was detected in several samples which were further classified into two categories by the regulation, i.e., rinse-off products and non-rinse-off products. Hand sanitizer, feminine hygiene, antiseptic soap, detergent, mouthwash, and laundry freshener were included in the rinse-off products. The triclosan levels in these six products were in the range of $0.024-0.321 \%$. Furthermore, deodorant, face mask, and face powder were included in non-rinse-off products, in which three product samples were identified to contain triclosan in the range of $0.024-0.070 \%$. All the determination results (Table-6) and revealed that the triclosan level in those products was not more than the permitted level according to regulation in Indonesia ( $2 \%$ for rinse-off products and $0.3 \%$ for non-rinse-off products).

Table-6: Analytical Results of Household, Personal Care, and Cosmetic Products by IRP-HPLC UV

\begin{tabular}{|c|c|c|c|c|c|}
\hline \multirow[t]{2}{*}{ No. } & \multirow[t]{2}{*}{ Samples } & \multicolumn{3}{|c|}{$\%$ Found $\pm \mathrm{SD}(\mathrm{N}=5)$} & \multirow[t]{2}{*}{ Maximum Level $^{19}(\%)$} \\
\hline & & Solid-base & Semisolid-base & Liquid-base & \\
\hline \multicolumn{6}{|c|}{ Rinse-off Products } \\
\hline 1. & Hand sanitizer & & $0.321 \pm 0.002$ & & \multirow{6}{*}{2} \\
\hline 2. & Laundry freshener & & & $0.029 \pm 0.002$ & \\
\hline 3. & Detergent & $0.024 \pm 0.000$ & & & \\
\hline 4. & Feminine hygiene & & $0.083 \pm 0.000$ & & \\
\hline 5. & Mouthwash & & & $0.125 \pm 0.006$ & \\
\hline 6. & Body wash liquid soap & & $0.208 \pm 0.001$ & & \\
\hline \multicolumn{6}{|c|}{ Non-Rinse-off Products } \\
\hline
\end{tabular}


RASĀYAN J. Chem.

Vol. 14 | No. 2 |1435-1440| April - June | 2021

\begin{tabular}{c|l|l|c|l|}
\hline 1. & Face masks & & $0.07 \pm 0.000$ & \\
\cline { 1 - 3 } 2. & Deodorant & & $0.040 \pm 0.000$ & \\
\cline { 1 - 3 } 3. & Face powder & $0.024 \pm 0.000$ & & \multirow{2}{*}{0.3} \\
\hline
\end{tabular}

\section{CONCLUSION}

An HPLC method equipped with C18 columns controlled at $30^{\circ} \mathrm{C}$, $\mathrm{UV}$ detection system at $280 \mathrm{~nm}$ and the mobile phase has been developed and was successfully applied for determination of triclosan in several household, personal care, and cosmetic products samples. The triclosan levels in those products were in the range of $0.024-0.321 \%$ which were not more than the maximum permitted level according to regulation in Indonesia.

\section{ACKNOWLEDGEMENT}

The author would like to thank BUDI DN No. 20161141041010 and LPDP Indonesia for their financial support.

\section{REFERENCES}

1. J. D. Lee, J. Y. Lee, S. J. Kwack, C. Y. Shin, H. J. Jang, H. Y. Kim, M. K. Kim, D. W. Seo, B. M. Lee and K. B. Kim, Toxicological Research. 35(2), 137(2019), DOI:10.5487/TR.2019.35.2.137

2. T. Liu, and D. Wu, International Journal of Cosmetic Science, 34, 489(2012), DOI:10.1111/j.14682494.2012.00742.x

3. N. Halla, I. P. Fernandes, S. A. Heleno, P. Costa, Z. B. Otmani, K. Boucherit, A. E. Rodrigues, I. C. F. R. Ferreira, and M. F. barreiro, Molecules, 23(1571), 1(2020), DOI:10.3390/molecules23071571

4. E. Manova, N. van Goetz, C. Keller, M. Siegrist, and K. Hungerbühler, International Journal of Environmental Research and Public Health, 10, 2778(2013), DOI:10.3390/ijerph10072778

5. H. Shaaban, and W. Alhajri, Journal of Environmental and Public Health, 2020, Article ID 8434508 (2020), DOI: $10.1155 / 2020 / 8434508$

6. J. W. H Biesterbos, T. Dudzina, C. J. E. Delmaar, M. I. Bakker, F. G. M. Russel, N. van Goetz, P. T. J. Scheepers, and N. Roeleveld, Food and Chemical Toxicology, 55, 8(2013), DOI:10.1016/j.fct.2012.11.014

7. A. B. Dann, and A. Hontela, Journal of Applied Toxicology, 31, 285(2011), DOI: 10.1002/jat.1660

8. D. Mackay, and L. Barnthouse, Integrated Environmental Assessment and Management, 6, 390(2010). DOI: 10.1002/ieam.73

9. X. May, D. H. Bennett, B. Ritz, D. L. Cassady, and K. Lee, and I. H. Picciotto, Food and Chemical Toxicology. 48, 3109(2010), DOI: 10.1016/j.fct.2010.08.004

10. S. Subramonian, S. Chandran, M. Murugan, and T. Murugan, Rasayan Journal of Chemistry, 9, 335(2016).

11. N. Aminu, S. Y. Chan, N. H. Khan, and S. M. Toh, Acta Chromatographica, 30, 219(2018), DOI: $10.1556 / 1326.2017 .00286$

12. R. K. Bhogadi, A. Satyanarayana, N. Someswara Rao, S. Arutla, and A. Malleswarareddy, Rasayan Journal of Chemistry, 7, 380(2014).

13. S. Shiyan, S. Shiyan, R. Martien, and A. K. Nugroho, Rasayan Journal of Chemistry, 12(3), 1098(2019), DOI: $10.31788 /$ RJC.2019.1235276

14. F. I. Nuryana, M. A. Chozin, and D. Guntoro, Rasayan Journal of Chemistry, 12(1), 360(2019), DOI: $10.31788 /$ RJC.2019.1215024

15. V. Sathiyanarayanan, H. Venkatasubramanian, and D. Easwaramoorthy, Rasayan Journal of Chemistry, 12, 2141(2019), DOI: 10.31788/RJC.2019.1245419

16. G. Ramanaiah, D. Ramachandran, G. Srinivas, J. Gowardhane, P. Rao, V. Srilakshmi, American Journal of Analytical Chemistrys, 3, 378(2012), DOI: 10.4236/ajac.2012.35050

17. Association of Official Analytical Chemist (AOAC), Official Methods of Analysis of the Association of Official Analytical Chemist International, 18th ed, Washington DC (2011)

18. W. Gottwald, Statistik fuer Anwender, Auflage, Wiley-VCH, Weinheim, 1, s. 89 - 146 (2000)

19. ASEAN Member countries, ASEAN Definition of Cosmetics and Illustrative List By Category of Cosmetic Products, 138 (2019).

[RJC-5861/2020] 